\title{
The Wits appraisal among a Nigerian sub-population: an assessment of dental base geometric factors
}

\author{
Ifesanya Joy Ucheonye ${ }^{1}$, Adeyemi Abigail Tokunbo', Otuyemi Olayinka Donald ${ }^{2}$ \\ 'Department of Child Oral Health, College of Medicine, University of Ibadan, Nigeria \\ ${ }^{2}$ Department of Child Dental Health, College of Health Sciences, Obafemi Awolowo University, Ile-Ife, Nigeria
}

\begin{abstract}
The Wits appraisal is a common linear cephalometric analytic tool established by Jacobson. It has been reported to be superior to angular cephalometric measures as it is not dependent on pericranial structures and their variations both during growth and orthodontic treatment. Aim: To obtain reference values for the Wits appraisal among Nigerians and assess the effect of the dental base geometry on it. Methods: Lateral cephalometric radiographs of 100 Nigerian subjects with normal occlusion were analyzed to obtain the Wits appraisal, and the effect of the vertical distance from subspinale to supramentale, length of the palatal and mandibular planes, the mandibular plane angle as well as the palatal plane angle were assessed using the ANOVA and linear regression analysis. Results: The mean age was $20.69 \pm 4.9$ years. Thirty-four $(34 \%)$ were males and $66(66 \%)$ were females. Mean Wits value of $-3.43 \pm 3.24 \mathrm{~mm}$ was obtained based on the functional occlusal plane (FOP). Linear regression analysis showed that the vertical height from subspinale (A point) to supramentale (B point) caused a significant change in the Wits appraisal reading in participants still undergoing active growth process (less than 16 years of age) $(p=0.02)$. Conclusions: It is advocated that the Wits appraisal be used as a moderator to the ANB angle among Nigerians. However, as a result of dental height variations its use in growing Nigerian children requires caution.
\end{abstract}

Keywords: Wits appraisal, Nigeria, dental base, cephalometry.

\section{Introduction}

Received for publication: June 10, 2013 Accepted: September 27, 2013

Correspondence to: Ifesanya Joy $U$ Orthodontic Unit, Department of Child oral Health,

College of Medicine

University of Ibadan, Nigeria,

Phone: +2348055623129

E-mail: joyifesanya@yahoo.co.uk
Radiographic analysis is useful in diagnosis, treatment monitoring and assessment of achieved goals at the end of orthodontic treatment. It also influences the course of treatment for malocclusion especially when decisions for or against extractions are involved ${ }^{1}$.

The ANB angle used in Steiner's analysis ${ }^{2-3}$ has been the most commonly used and possibly the simplest radiographic parameter in sagittal skeletal base position assessments ${ }^{4}$. However, the reliability of the ANB angle has been reported to be dependent on the antero-posterior position of the nasion and the subspinale ${ }^{5}$, the length of the cranial base, the inclination of the mandible in reference to the anterior cranial base, inclination of the occlusal plane, and the vertical dental height from A to B points ${ }^{5-8}$. Thus, the ANB may not always offer an accurate data for the antero-posterior relationships of the jaws ${ }^{9}$. Numerous cephalometric parameters have been proposed as adjuncts to the $\mathrm{ANB}^{10-14}$. 
The Wits appraisal, which is based on the occlusal plane, was established by Jacobson ${ }^{9,15-16}$ in 1975. It has become one of the most popular linear cephalometric modalities used in assessing orthodontic patients. Its primary importance is to serve as a source of supplementary information used in conjunction with the ANB angle for assessment of sagittal skeletal base discrepancies. This is expedient in patients whose angular cephalometric (ANB) value show great divergence from the clinical assessment. Since the Wits appraisal does not use cranial or pericranial landmarks, it should, theoretically, give a more accurate picture of any anteroposterior skeletal disharmonies existing between the maxilla and the mandible ${ }^{17}$. The Wits appraisal has been reported to show no significant age changes in people with normal occlusion ${ }^{18}$ though contrary report exists ${ }^{19}$. The assessment of sagittal jaw positions using the Wits appraisal is however reported to be affected by the inclination of the occlusal plane $^{20}$ and the vertical distance from the A to the B point ${ }^{11}$.

This study presents reference values for the Wits appraisal among a group of Nigerians and investigates the effect of the dental base geometry on it.

\section{Material and methods}

Ethical approval was obtained from the University of Ibadan/ University College Hospital Ethical Review Board. Participants with normal occlusion based on the following criteria were recruited from secondary and tertiary institutions in Ibadan, Nigeria (Figures 1a , 1b).

1. Age between 11-30years of age

2. Angle's class I molar relationship

3. Overjet between $2-4 \mathrm{~mm}$ and overbite not exceeding half of the labial surface of the lower incisors

4. Arch crowding or spacing not exceeding $2 \mathrm{~mm}$

5. No buccal or lingual crossbites

6. No rotations of teeth

7. A coincident midline

8. No supernumeraries or congenitally missing teeth with the exception of the third molars

9. No previous exodontia of permanent teeth

Non-Nigerians or those of mixed origin as well as individuals with special needs and other craniofacial anomalies were excluded from the study. All participants had never had orthodontic treatment.

Intraoral examination was performed by the principal investigator (IJU) under natural light using a sterile wooden spatula and a dental mirror. Lateral cephalometric radiographs of all participants were taken(Blue-X Imaging S/no 2402kk0164 ASSAGO, ITALY) with participants' head held in a cephalostat, looking forward with the Frankfort horizontal plane parallel to the floor and the teeth in maximum intercuspation. The distance from mid-sagittal plane of each participant to the source of radiation and the film was maintained at $150 \mathrm{~cm}$ and $15 \mathrm{~cm}$ respectively. Soft and hard tissue tracings were obtained manually on a 0.003 inch matte finish acetate tracing paper and a sharpened $2 \mathrm{H}$ pencil over a light viewing box in a dark room. The A point (subspinale: located on the deepest point on the anterior outline of the bony maxilla), B point (supramentale: located on the deepest point on the anterior outline of the bony mandible) as well as the functional occlusal plane (defined by a straight line passing through the intercuspation of the first premolar and the first molar) were determined. The Wits appraisal was obtained by projecting straight lines from the $\mathrm{A}$ and $\mathrm{B}$ points respectively unto the functional occlusal plane at $90^{\circ}$ and measuring the horizontal distance form point $\mathrm{AO}$ to $\mathrm{BO}$ (Figure 2). The vertical distance from subspinale to supramentale, the length of the palatal and mandibular planes, the mandibular plane angle and the palatal plane angle were also ascertained.

Intraexaminer variability was assessed by retracing 20 randomly selected radiographs at a two-week interval. The correlation coefficient was used for assessment of variability of measurements. Correlation value of $0.88(p<0.01)$ was obtained, showing an acceptable level of agreement between both readings.

Data was analyzed using the Statistical Package for Social Sciences (SPSS), version 19 (SPSS, Inc., Chicago, IL, USA). The t-test was used to assess any gender-based difference in the Wits appraisal. The ANOVA was used to assess the relationship between the Wits appraisal values and the other dental base factors, while linear regression analysis was used for assessing the effect of growth phase on the Wits appraisal. The level of significance was set at $p<0.05$.

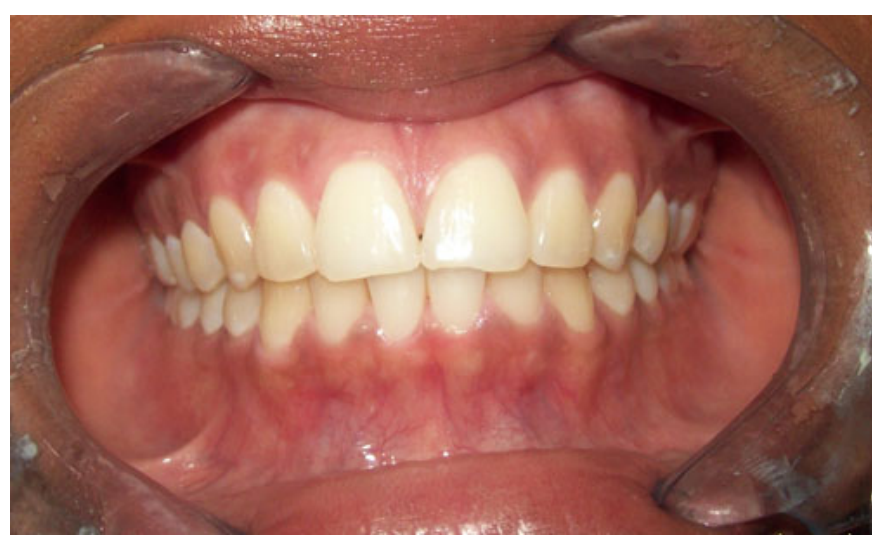

Fig. 1a - Facial intra-oral view of a participant with class I normal occlusion

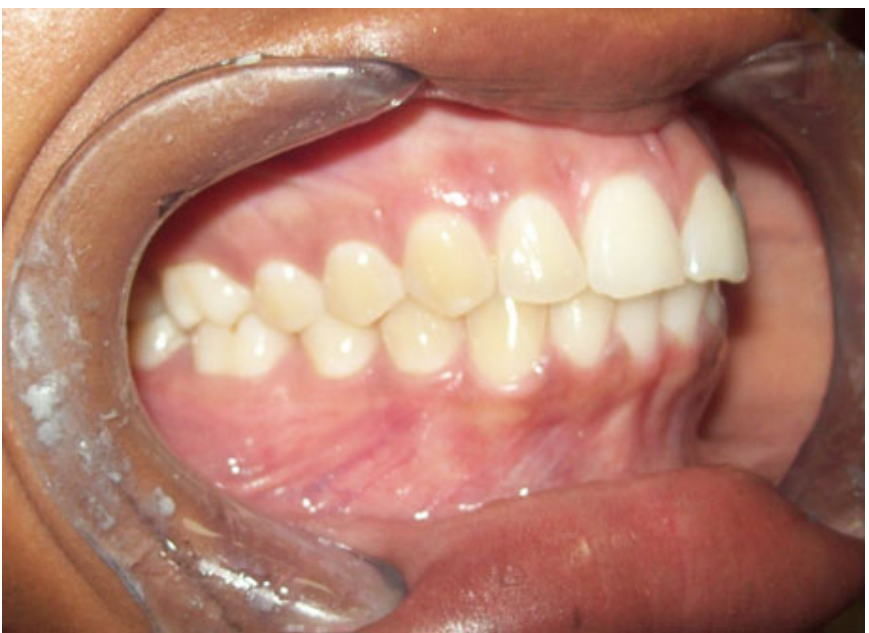

Fig. 1b - Profile intra-oral view of a participant with class I normal occlusion 


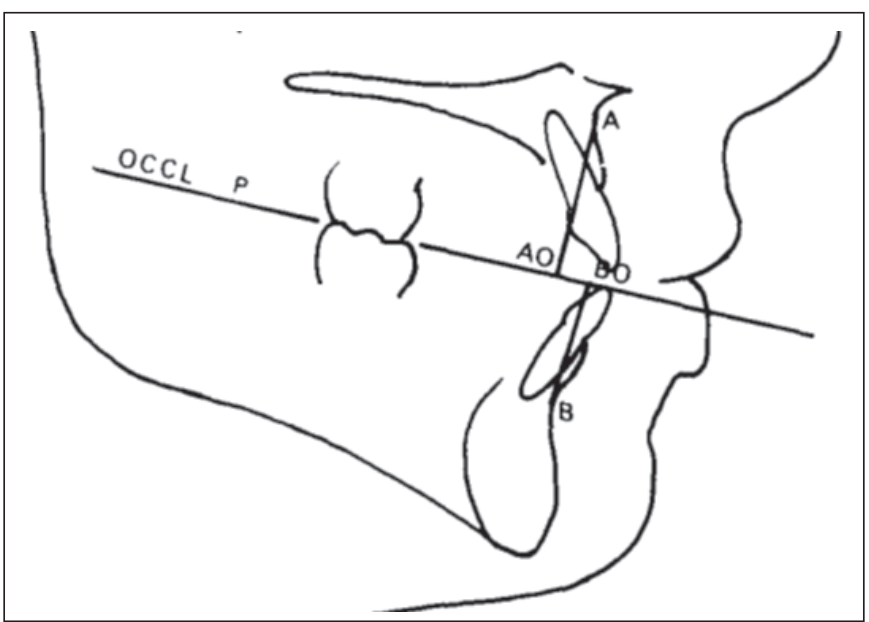

Fig. 2 - The Wits appraisal

\section{Results}

One hundred participants were evaluated, with mean age of 20.69 \pm 4.9 years (age range of 11-30 years), and the majority $(66 \%)$ being females. Though all participants had class I molar relationship and clinical type I facial profile, $48 \%$ of them were radiographically determined to be class I skeletal pattern, $35 \%$ were class II, and $17 \%$ were class III based on the ANB. However, using the Wits appraisal, 68\% were class I skeletal pattern, $17 \%$ were class II and $15 \%$ were class III. This difference in diagnostic accuracy was statistically significant $(\mathrm{p}<0.01)$ as shown in Table 1.

Linear cephalometric values for the Wits appraisal using the functional occlusal plane (FOP) showed a range of $-12 \mathrm{~mm}$ to $3.5 \mathrm{~mm}$ (mean $-3.43 \pm 3.24 \mathrm{~mm}$ ). Gender distribution of the Wits values did not show any significant variation (Table 2). One-way ANOVA showed no significant variation in the Wits appraisal values with respect to the vertical distance from the subspinale to the supramentale, length of the palatal or mandibular plane as well as the mandibular or palatal plane angles (Table 3). A linear regression model constructed based on age of the participants showed that with exception of the vertical dental base height $(p<0.05)$, the skeletal base variables caused no significant change $(p>0.05)$ in the Wits appraisal values among participants still actively growing (age of 16 years and less). However, among those in whom active growth had ceased none of the dental base factors was associated with a significant change $(p>0.05)$ in the Wits appraisal value (Table 4).

\section{Discussion}

The Wits appraisal obtained from this study using the functional occlusal plane as originally described reveals a more negative value than that reported by Jacobson ${ }^{9}$. Results similar to Jacobson's have been reported among the Saudi, Cappadocian, Turkish and American populations ${ }^{21-23}$. A Southern Chinese study had reported a similar finding to that obtained in this study ${ }^{24}$. Nigerians exhibit bi-maxillary protrusion $^{25}$ and this may be responsible for the difference in Wits appraisal values.

It has been established that angular measurements do not compensate for facial divergence hence linear measurements such as the Wits appraisal offer a more reliable assessment of sagittal skeletal base discrepancy irrespective of the degree of malocclusion ${ }^{26}$. In congruence with this, the stability of the Wits appraisal values in the studied population, especially among those who have passed their active growth phase, may mean that the Wits appraisal in itself is a sufficient diagnostic tool among this group of people. However in actively growing patients, caution must be exercised because of the effect of the vertical dental base height: a finding corroborating a previous report ${ }^{19}$. A recent study reported no change in the Wits appraisal in the 8-14year-old age group in Class I subjects with clinically acceptable occlusion and subjects with class III malocclusion ${ }^{27}$. Similarly, the ANB and Wits appraisal obtained from $\mathrm{CBCT}$ images has been reported not to show any significant correlation with age. The latter study however assessed a sample with a wide age disparity ${ }^{28}$ and this wide age gap might have masked the true influence of age in the sample. This study found no significant influence of age on the Wits appraisal only among participants older than 16 years.

On the other hand, it has been shown that the ANB and Wits appraisal decreased among cleft lip, alveolus and palate

Table 1. Classification of participants' skeletal pattern as obtained using ANB angle and Wits appraisal among participants with normal occlusion.

\begin{tabular}{lcccc}
\hline Variable & $\begin{array}{c}\text { Class I } \\
\text { Malocclusion } \\
\mathbf{N}(\%)\end{array}$ & $\begin{array}{c}\text { Class II } \\
\text { Malocclusion } \\
\mathbf{N}(\%)\end{array}$ & $\begin{array}{c}\text { Class III } \\
\text { Malocclusion } \\
\mathbf{N}(\%)\end{array}$ & $\begin{array}{c}\text { Total } \\
\mathbf{N}(\%)\end{array}$ \\
ANB angle & $48(48)$ & $35(35)$ & $17(17)$ & $100(100)$ \\
MM $^{\circ}$ bisector plane Wits appraisal & $70(70)$ & $14(14)$ & $16(16)$ & $100(100)$ \\
BOP Wits appraisal & $68(68)$ & $17(17)$ & $15(15)$ & $100(100)$ \\
FOP Wits appraisal & $68(68)$ & $17(17)$ & $15(15)$ & $100(100)$ \\
\hline
\end{tabular}

Table 2. Gender distribution of Wits appraisal.

\begin{tabular}{llccc}
\hline Gender & N & Mean \pm Std. Desviation $(\mathrm{mm})$ & F-test score & p value \\
Male & 34 & $-4.15 \pm 3.65$ & 2.744 & 0.10 \\
Female & 66 & $-3.06 \pm 2.96$ & & \\
\hline
\end{tabular}


Table 3. Relationship between Wits appraisal values and dental base geometry

\begin{tabular}{|c|c|c|c|}
\hline Dental base geometric variable & Mean \pm Std. Desviation $(\mathrm{mm})$ & F test score & $p$-value \\
\hline Vertical distance from $a$ to $b$ point & $44.3 \pm 0.4$ & 1.09 & 0.38 N.S \\
\hline Length of anterior cranial base & $71.2 \pm 0.6$ & 0.86 & $0.66^{N . S}$ \\
\hline Length of palatal plane & $55.7 \pm 0.4$ & 1.35 & $0.16^{N . S}$ \\
\hline Length of mandibular plane & $83.6 \pm 0.6$ & 0.86 & $0.66^{\mathrm{N} . \mathrm{S}}$ \\
\hline Mandibular plane angle & $32.6 \pm 0.6$ & 1.08 & $0.38^{\mathrm{N} . \mathrm{S}}$ \\
\hline Palatal plane angle & $6.3 \pm 0.3$ & 0.74 & $0.80^{\mathrm{N} . \mathrm{S}}$ \\
\hline Maxillomandibular plane angle & 27. $2 \pm 0.5$ & 1.15 & $0.31^{\mathrm{N} . \mathrm{S}}$ \\
\hline
\end{tabular}

Table 4. Influence of growth on the relation of wits appraisal and dental base geometry

\begin{tabular}{llllllll}
\hline \multirow{2}{*}{ Variable } & \multicolumn{3}{c}{ Age $\leq 16$ years } & \multicolumn{3}{c}{ Age >16 years } \\
Mandibular plane angle & 0.69 & -2.49 & 1.71 & 0.188 & -0.143 & 0.715 \\
Palatal plane angle & 0.51 & -1.41 & 2.71 & 0.640 & -0.601 & 0.372 \\
Length palatal plane & 0.47 & -0.31 & 0.62 & 0.319 & -0.122 & 0.368 \\
Length mandibular plane & 0.20 & -0.56 & 0.13 & 0.677 & -0.120 & 0.183 \\
Vertical distance A to B point & $0.02^{*}$ & -1.27 & -0.14 & 0.314 & -0.328 & 0.107 \\
Maxillomandibular plane angle & 0.63 & -1.68 & 2.69 & 0.711 & -0.479 & 0.320 \\
\hline${ }^{*}$-significant & & & & & &
\end{tabular}

patients from serial cephalograms taken at ages 10,15 and 18 years $^{29}$. A similar finding was repeated among 10-14year-old Chinese children ${ }^{30}$ and our study corroborates this finding in participants aged 16 years and younger.

Roth's proposal of projecting the Wits measurement from a standardized point $50 \mathrm{~mm}$ along the vertical distance $\mathrm{AB}$ to the occlusal plane (the Wits ${ }_{50}$ ) as a means of eliminating the effect of the vertical dental height among growing patients ${ }^{19}$ may be applicable in growing Nigerian children. An added advantage of using Wits $_{50}$ is that it describes the molar relationship relative to the occlusal plane and presents a better separation among cases in the three classes of malocclusion ${ }^{19}$.

The difference in diagnostic accuracy between the ANB angle and the Wits appraisal shows the Wits appraisal as being more reliable than the ANB in assessment of sagittal dental base discrepancy. This is similar to findings from other studies $^{9,31-32}$ and, based on this, it is wise to use the Wits appraisal as a moderator of the ANB angle in the management of orthodontic patients.

In conclusion, despite the obvious advantages of the Wits appraisal, using it as a moderator of the ANB angle among Nigerians must be done with caution. This is pertinent especially in actively growing children where the effect of dental height variations may confound Wits value.

\section{References}

1. Kannan S, Goyaliya A, Gupta R. Comparative assessment of sagittal maxillo-mandibular jaw relationship - a cephalometric study. J Oral Health Comm Dent. 2012; 6: 14-7.

2. Steiner CC. Cephalometrics for you and me. Am J Orthod. 1962; 39: 720-55.

3. Oktay HA. A comparison of ANB, Wits , AF-BF and APDI measurement. Am J Orthod. 1975; 99: 122-8.

4. Italia S, Bhatia AF. Palatal plane and thier comparison with "angle ANB" and "Wits appraisal": A cephalometric study. JAhmedabad Dental College Hosp. 2011; 2: 22-6.
5. Rotberg S, Fried N, Kane J, Shapiro E. Predicting the "Wits" appraisal from the ANB angle. Am J Orthod. 1980; 77: 636-42.

6. Bishara SE, Fahl JA, Peterson LC. Longitudinal changes in ANB angle and wits appraisal: clinical implications. Am J Orthod Dentofac Orthop. 1983; 84: 133-9.

7. McNamara JA. A method of cephalometric evaluation. Am J Orthod. 1984; 86: 449-69.

8. Freeman RS. Adjusting ANB angles to reflectthe effect of maxillary position. Angle Orthod. 1981; 51: 162-171.

9. Jacobson A. The "Wits" appraisal of jaw disharmony. Am J Orthod. 1975; 124: 470-9.

10. Nanda RS, Merill RM. Cephalometric assessment of sagittal relationship between maxilla and mandible. Am J Orthod Dentofac Orthop. 1994; 105: 328-44.

11. Chang HP. Assessment of anteroposterior jaw relationship. Am J Orthod Dentofac Orthop. 1987; 92: 117-22.

12. Yang SD, Suhr $\mathrm{CH}$. F-H to $A B$ plane angle(FABA) for assessment of antero-posterior jaw relationships. The Angle orthodontist. 1995; 65: 223-31.

13. Sarhan O.Anew cephalometric parameter to aid in dental base relationship analysis. Angle Orthod. 1990; 60: 59-63.

14. Kim YH, Vietas JJ. Anteroposterior dysplasia indicator: an adjunct to cephalometric differential diagnosis. Am J Orthod. 1978; 73: 619-33.

15. Jacobson A. Application of Wits appraisal. Am J Orthod. 1976; 70: 179-89.

16. Jacobson A. Update on the Wits appraisal. Angle Orthod. 1988; 58: 205-19.

17. Jabbar A, Mahmood A. Correlation of overjet, ANB and wits appraisal for assessment of sagittal skeletal relationship. Pakistan Orthod J. 2012; 4: 17-23.

18. Lux CJ, Burden D, Conradt C, Komposch G. Age-related changes in sagittal relationship between the maxilla and mandible. Eur J Orthod. 2005; 27:568-78.

19. Roth R. The "Wits" appraisal - its skeletal and dento-alveolar background Eur J Orthod . 1982; 4: 21-8.

20. Sachdeva K, Singla A, Mahajan V, Jaj HS Seth V, Nanda M. Comparison of different angular measurements to assess sagittal skeletal discrepancy-A cephalometric study. Indian J Dent Sci. 2012; 4: 27-9.

21. Al-barakati SF. The wits appraisal in a Saudi population sample. Saudi Dent J. 2002; 14: 89-92

22. Ramoðlu SÝ, Yaðci A, Uysal T. Wits Appraisal in Cappadocian Turkish Population. J Health Sci. 2009; 18: 111-7.

23. Davis GS, Cannon JL, Messersmith ML. Determining the sagittal relationship between the maxilla and the mandible/ :Acephalometric analysis to clear up the confusion. J Tennessee Dent Assoc. 2013; 22-30.

24. So LLY, Dvis JP, King NM. Wits appraisal in Southern Chinese children. Angle Orthod. 1990; 60: 43-8. 
25. Isiekwe MC, Sowemimo GOA. Cephalometric findings in a normal Nigerian population sample and adults with unrepaired clefts. Cleft palate journal. 1984; $21: 323-8$.

26. Kapoor DN, Chandna A, Shalini T. Linear assessment of anteroposterior jaw relationships. J Indian Soc Pedo Prev Dent. 2004; 22: 187-92.

27. Chen F, Terada K, Wu L, Saito I. Longitudinal Evaluation of the Intermaxillary Relationship in Class III Malocclusions. Angle Orthod. 2006; 76: 955-61.

28. Zamora N, Cibrián R, Gandia J, Paredes V. Study between anb angle and Wits appraisal in cone beam computed tomography(CBCT ). Med Oral Patol Oral Cir Bucal. 2013; 18: e725-32.

29. Lisson JA, Heib N, von Moeller S Spitzer WJ, Ludwig B. Treatment result at 10,15 and 18 years of age in patients with complete bilateral cleft lip and palate: An intercentre comparison. Cleft Palate Craniofac J. 2013; 50: 19-24.

30. Wu JYC, Hägg U, Wong RWK, McGrath C. Comprehensive cephalometric analyses of 10 to 14 year old Southern Chinese. Open Anthropol J. 2010; 3: 85-95.

31. Zhou L, Mok C-W, Hägg U, McGrath C, Bendeus M, Wu J. Anteroposterior dental arch and jaw-base relationships in a population sample. Angle Orthod. 2008; 78: 1023-9.

32. Shendre S, Karan GK, Ravinarayana RPR, Mamtha T. Correlation of the anteroposterior relationships of the dental arch and jaw-base in subjects with class I, class II and class III malocclusions. Int J Contemporary Dent. 2011; 2: 68-73. 